\title{
Controlled Aspect Ratios of Gold Nanorods in Reduction-Limited Conditions
}

\author{
Jong-Yeob Kim, ${ }^{1}$ Chil Seong Ah, ${ }^{1,2}$ and Du-Jeon Jang ${ }^{1}$ \\ ${ }^{1}$ School of Chemistry, Seoul National University, NS60, Seoul 151-747, Republic of Korea \\ ${ }^{2}$ Electronics and Telecommunications Research Institute, Daejeon 305-700, Republic of Korea
}

Correspondence should be addressed to Du-Jeon Jang, djjang@snu.ac.kr

Received 13 December 2010; Revised 5 March 2011; Accepted 28 April 2011

Academic Editor: Ping Xiao

Copyright (C) 2011 Jong-Yeob Kim et al. This is an open access article distributed under the Creative Commons Attribution License, which permits unrestricted use, distribution, and reproduction in any medium, provided the original work is properly cited.

\begin{abstract}
Aspect ratios of gold nanorods have been finely modified in reduction-limited conditions via two electrochemical ways: by changing the amount of a growth solution containing small gold clusters in the presence of already prepared gold nanorods as seeds or by changing electrolysis time in the presence or absence of a silver plate. While the atomic molar ratio of gold in the growth solution to gold in the seed solution is critical in the former method, the relative molar ratio of gold ions to silver ions in the electrolytic solution is important in the latter way for the control of the aspect ratios of gold nanorods. The aspect ratios of gold nanorods decrease with an increase of electrolysis time in the absence of a silver plate, but they increase with an increase of electrolysis time in the presence of a silver plate.
\end{abstract}

\section{Introduction}

The design and controlled fabrication of nanostructured materials with functional properties have been extensively investigated to attract a great deal of attention [1-7]. A great number of inventive techniques involving chemical, electrical, and optical processes have been employed to synthesize monodispersive and anisotropic materials of nanorods (NRs), nanowires, and nanobelts [8-12]. In particular, one-dimensional gold nanostructures have been extensively studied due to their potential in a variety of applications such as biosensing, molecular imaging, and photothermal therapy [13-17]. Gold NRs with diverse aspect ratios have drawn considerable attention because of their optical properties, exhibiting intense longitudinal and transverse plasmon bands in the visible region [18-23].

The synthesis of aspect ratio-controlled gold NRs is important because it leads us to explore their properties and to find their applications in sensing and imaging nanoscience. Several approaches such as seeding [22-24], ultrasonic [25], photochemical [20, 26, 27], and electrochemical methods [28-36] have been carried out to control the aspect ratios of gold NRs. We also note that bioreduction techniques $[37,38]$ have been applied to study faceting and surface reconstruction on gold. The electrochemical synthesis of gold NRs has been proven to have some additional advantages over chemical methods although the growth mechanism of gold NRs during the electrochemical synthesis remains elusive [20]. The aspect ratios of gold NRs have been controlled generally by changing the gold atomic concentration ratio of the growth solution to the seed solution or by varying the amount of silver ions [18$23,32-35]$. The use of silver ions to assist the growth of gold NRs is common in a seed-mediated approach. It has been noted that the addition of a small amount of silver ions is critical for the formation of gold NRs instead of spherical gold nanoparticles $[20,23,32-35]$. However, the roles of silver ions in the determination of the aspect ratios of gold NRs have not been fully understood yet regardless of many reports $[18,23]$.

In this paper, we report that the aspect ratio modification of gold NRs can be approached in two electrochemical ways: by changing the amounts of growth solutions or by changing electrolysis time in the presence or absence of a silver plate. While the gold atomic molar ratio of the growth solution to the seed solution is critical in the former method, the relative atomic molar ratio of gold to silver is found to be important in the latter way to control the aspect ratios of gold NRs. 


\section{Materials and Methods}

The synthesis of a seed solution was conducted using a simple electrochemical cell [28]. A gold plate $\left(3 \times 1 \times 0.05 \mathrm{~cm}^{3}\right)$ and a platinum plate $\left(3 \times 1 \times 0.05 \mathrm{~cm}^{3}\right)$ were used as the anode and the cathode, respectively. Spacing between the anode plate and the cathode plate was kept at $0.25 \mathrm{~cm}$. Both electrodes were immersed in $6 \mathrm{~mL}$ of an electrolytic solution containing $80 \mathrm{mM}$ hexadecyltrimethylammonium bromide $(\mathrm{CTAB})$ as a hydrophilic cationic surfactant and $8.0 \mathrm{mM}$ tetraoctylammonium bromide as a hydrophobic cationic cosurfactant $[18,28]$. Immediately prior to electrolysis, $0.13 \mathrm{~mL}$ of acetone and $0.09 \mathrm{~mL}$ of cyclohexane were added into the electrolytic solution. While current was typically set at $5 \mathrm{~mA}$, temperature was maintained roughly at $38^{\circ} \mathrm{C}$ throughout electrolysis. A silver metal plate $(3 \times 1 \times$ $0.05 \mathrm{~cm}^{3}$ ) was immersed into the electrolytic solution. $6 \mathrm{~mL}$ of an aqueous solution containing gold clusters $(<1 \mathrm{~nm}$ in diameter) was prepared for a growth solution using the above-mentioned electrochemical method. The color of the solution was pale blue when the electrolysis was over. Gold clusters of the growth solution were too small for their sizes to be measured using transmission electron microscopy (TEM). Growth solutions were used within $5 \mathrm{~min}$ after being prepared to prevent spontaneous nucleation into gold NRs. Aspect ratios of gold NRs were controlled by adding various amounts of gold cluster solutions as growth solutions to fixed amounts $(0.1 \mathrm{~mL})$ of gold NR solutions as seed solutions to make the gold atomic molar ratios $\left(w_{0}\right)$ of growth solutions to seed solutions be $0,1.5,1.75,2$, and 3 . To modify the aspect ratios of gold NRs by changing electrolysis time, a silver plate was inserted in the electrolytic solution of the above mentioned simple electrochemical cell having a gold plate as the anode and a platinum plate as the cathode. Firstly, we applied electric current for $10 \mathrm{~min}$ to the electrolytic solutions having a silver plate. Secondly, in one experiment, the silver plate was removed from the electrolytic solution, and then electric current was additionally applied for 5,10 , or $15 \mathrm{~min}$ with a typical current setting of $5 \mathrm{~mA}$. In the other experiment, electrolysis was continuously operated with the silver plate for up to $25 \mathrm{~min}$. A comparative study with and without a silver plate was carried out to understand the effect of silver ions on the surface-plasmon resonances and the aspect ratios of gold NRs.

The absorption spectra of the aqueous colloidal solutions of gold NRs contained in quartz cells having a path length of $2 \mathrm{~mm}$ were taken using a UV/vis spectrophotometer (Scinco, UVS2040). A drop of a gold colloidal solution was placed on a carbon-coated copper grid for the TEM measurement using a microscope (JEOL, JEM2000).

\section{Results and Discussion}

Figure 1 shows the absorption spectra of gold NRs prepared at different $w_{0}$ values. The absorption spectrum of gold NRs prepared in the absence of the growth solution has the longitudinal plasmon maximum at $748 \mathrm{~nm}$ (Figure 1(a)). As the $w_{0}$ value increased gradually from 0 to 3 , the wavelength at the absorption maximum of the longitudinal plasmon

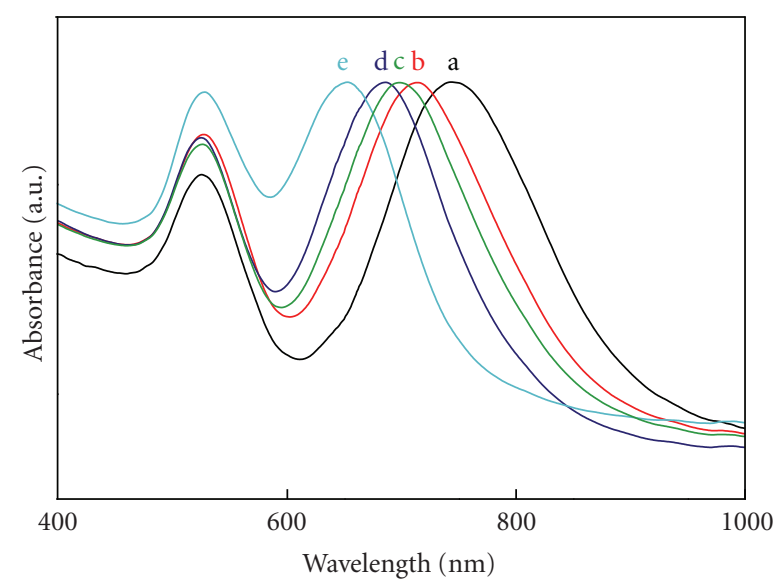

Figure 1: Absorption spectra for gold NR solutions prepared by being set aside for 2 days at various $w_{0}$ values of 0 (a), 1.5 (b), 1.75 (c), 2 (d), and 3 (e).

mode $\left(\lambda_{L}\right)$ shifts to the blue continuously and largely. Table 1 indicates that $\lambda_{L}$ at $w_{0}=3$ is shorter by $95 \mathrm{~nm}$ than $\lambda_{L}$ at $w_{0}=$ 0 . However, the wavelength at the absorption maximum of the transverse plasmon mode $\left(\lambda_{T}\right)$ shifts gradually and very slightly to the red with an increase of the $w_{0}$ value. The extreme shift of $\lambda_{L}$ to the blue and the slight shift of $\lambda_{T}$ to the red indicate that the aspect ratios of gold NRs decrease extensively and continuously with an increase of $w_{0}$ value. Thus, this suggests that we can control the aspect ratios of gold NRs by adjusting the $w_{0}$ value.

The TEM images of Figure 2 clearly show that the mean diameter of gold NRs increased continuously with an increase of the $w_{0}$ value. However, the mean length of gold NRs remained almost invariant regardless of the variation of the $w_{0}$ value. These imply that the aspect ratios of gold NRs decreased as the $w_{0}$ value increased (Table 1). From these observations it can be inferred that the gold seeds were grown more easily on the side of gold NRs than on the ends of gold NRs. It is known that the rarely observed $\{110\}$ facets of gold NRs has higher energy than the $\{111\}$ and $\{100\}$ facets of gold NRs do [30, 33, 39-42]. In previous other seeding methods, which employed small nanoparticles as seeds, the aspect ratios of gold NRs were reported to increase with an increase of the $w_{0}$ value because the growth of gold NRs was assisted by the aqueous micellar template of CTAB $[18,22,24]$. However, if gold NRs were used as seeds, the diameters grew faster than the lengths did. As the $w_{0}$ value increased from 0 to 2 , the average length of gold NRs increased only $3.3 \%$ whereas the average diameter of gold NRs increased by $27 \%$ (Table 1). So the use of already prepared gold NRs as seeds is considered to be important for the fine modification of the aspect ratios of gold NRs.

On one hand, Figure 3(a) shows that the wavelength at the longitudinal absorption maximum of gold NRs dispersed in water decreased linearly with an increase of the $w_{0}$ value. This implies that the optical properties of gold NRs can be tuned finely to cover a wide spectral range of 748-653 nm by adjusting the $w_{0}$ value, as described with Figure 1 . On the other hand, Figure 3(b) reveals that the average aspect 
TABLE 1: Wavelengths at longitudinal absorption peaks $\left(\lambda_{L}\right)$, average lengths $(l)$, average diameters $(d)$, and average aspect ratios $(A R)$ for the gold NRs of the samples described in Figures 1 and 2.

\begin{tabular}{|c|c|c|c|c|c|}
\hline Figures & $w_{0}{ }^{\mathrm{a}}$ & $\lambda_{L}(\mathrm{~nm})$ & $l(\mathrm{~nm})$ & $d(\mathrm{~nm})$ & $A R$ \\
\hline Figures $1(\mathrm{a})$ and 2(a) & 0.00 & 748 & 36.6 & 10.4 & 3.6 \\
\hline Figures $1(\mathrm{~b})$ and 2(b) & 1.50 & 714 & 36.4 & 11.7 & 3.2 \\
\hline Figures $1(\mathrm{c})$ and $2(\mathrm{c})$ & 1.75 & 699 & 37.9 & 12.9 & 3.0 \\
\hline Figures $1(\mathrm{~d})$ and $2(\mathrm{~d})$ & 2.00 & 687 & 37.8 & 13.2 & 2.9 \\
\hline Figures $1(\mathrm{e})$ and $2(\mathrm{e})$ & 3.00 & 653 & 36.9 & 14.8 & 2.5 \\
\hline
\end{tabular}

${ }^{a}$ Gold atomic molar ratio of the growth solution to the seed solution.

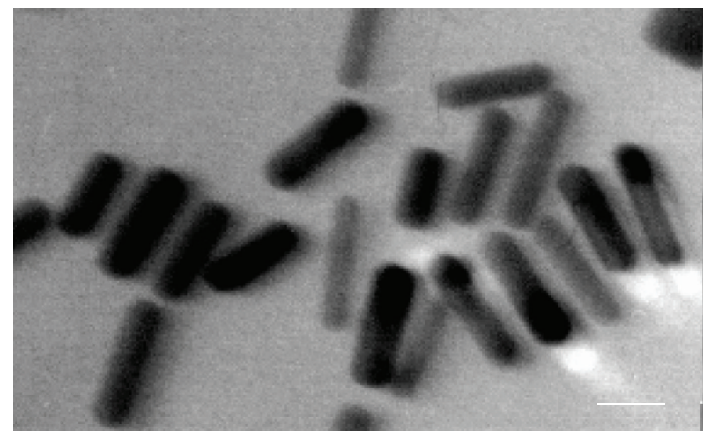

(a)

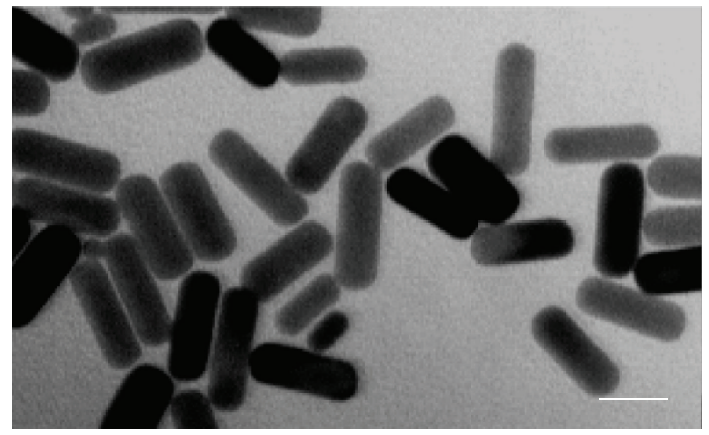

(c)

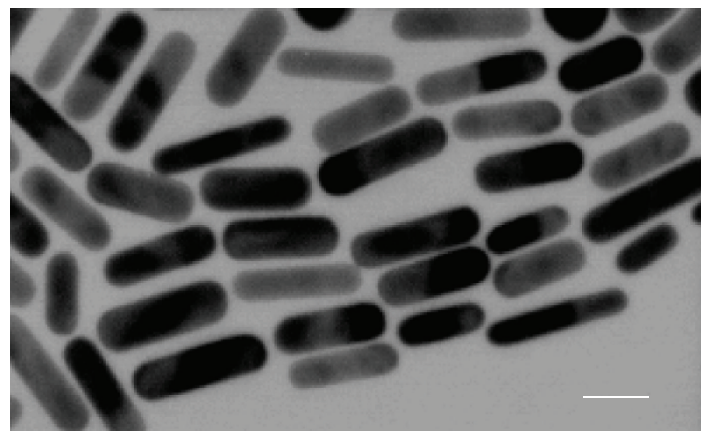

(b)

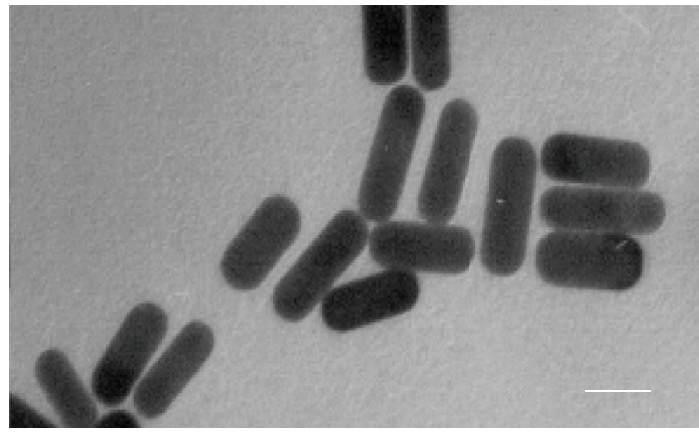

(d)

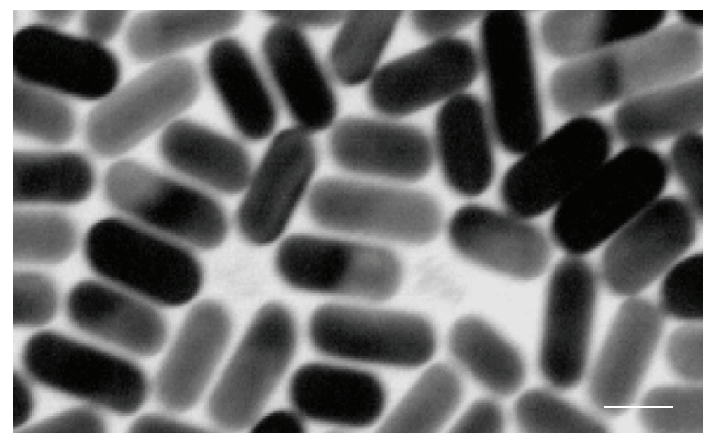

(e)

FIGURE 2: TEM images of gold NRs prepared by being set aside for 2 days at various $w_{0}$ values of 0 (a), 1.5 (b), 1.75 (c), 2 (d), and 3 (e). Each scale bar indicates $25 \mathrm{~nm}$.

ratio of gold NRs decreased linearly from 3.6 to 2.5 as the $w_{0}$ value increased from 0 to 3 . As discussed with Figure 2, this suggests that the aspect ratios of gold NRs can be modified finely by adjusting the $w_{0}$ value.

To modify the aspect ratios of gold NRs by changing electrolysis time, a silver plate was inserted to a simple electrochemical cell having a gold plate as the anode and a platinum plate as the cathode. Figure 4(a) shows the absorption spectrum of gold NRs prepared by applying the electric current to the electrolytic solution for $10 \mathrm{~min}$ in the presence of a silver plate. Then, the silver plate was removed from the electrolytic solution, and the electric current was applied additionally to the electrolytic solution for 5 (Figure 4(b)), 10 (Figure $4(\mathrm{c})$ ), or $15 \mathrm{~min}$ (Figure 4(d)). Table 2 indicates 
TABLE 2: Wavelengths at longitudinal absorption peaks $\left(\lambda_{L}\right)$, average lengths $(l)$, average diameters $(d)$, and average aspect ratios $(A R)$ for the gold NRs of the samples described in Figures 4 and 5.

\begin{tabular}{|c|c|c|c|c|c|}
\hline Figures & Time $(\min )^{\mathrm{a}}$ & $\lambda_{L}(\mathrm{~nm})$ & $l(\mathrm{~nm})$ & $d(\mathrm{~nm})$ & $A R$ \\
\hline Figures $4(\mathrm{a})$ and 5(a) & 0 & 674 & 36.7 & 13.7 & 2.7 \\
\hline Figures 4(b) and 5(b) & 5 & 740 & 61.7 & 18.9 & 3.3 \\
\hline Figures 4(c) and 5(c) & 10 & 655 & 58.9 & 24.5 & 2.4 \\
\hline Figures $4(\mathrm{~d})$ and $5(\mathrm{~d})$ & 15 & 630 & 50.1 & 23.9 & 2.1 \\
\hline
\end{tabular}

${ }^{a}$ Additional electrolysis period after removing the silver plate.

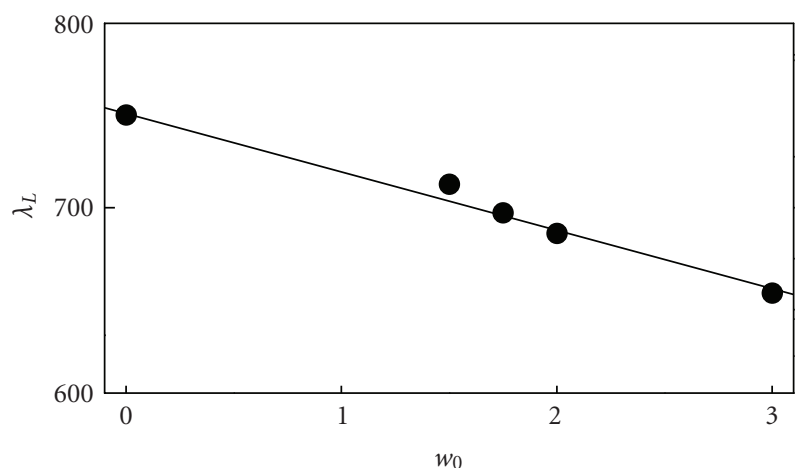

(a)

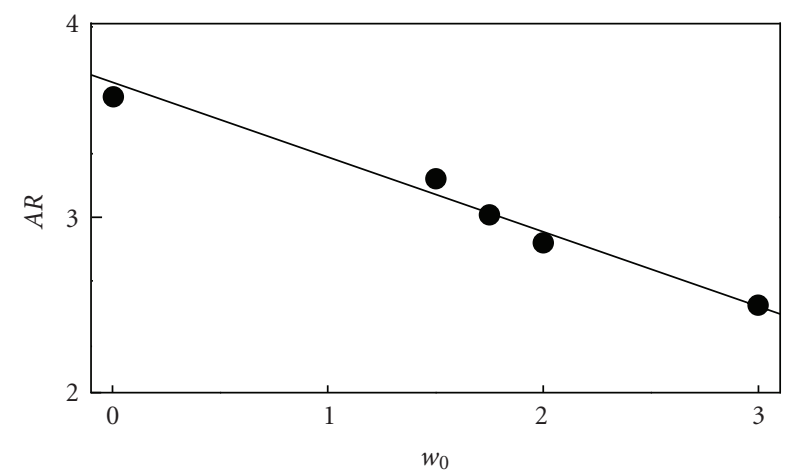

(b)

Figure 3: $\lambda_{L}$ (a) and $A R(\mathrm{~b})$ of gold NRs versus $w_{0}$ for the samples described in Figures 1 and 2.

that $\lambda_{L}$ at $5 \mathrm{~min}$ was shifted largely (by $66 \mathrm{~nm}$ ) to the long wavelength compared with $\lambda_{L}$ at $0 \mathrm{~min}$. However, $\lambda_{L}$ at $10 \mathrm{~min}$ and $\lambda_{L}$ at $15 \mathrm{~min}$ were shifted gradually to the short wavelength compared with $\lambda_{L}$ at 0 min. Table 2 indicates that $\lambda_{L}$ at $10 \mathrm{~min}$ and $\lambda_{L}$ at $15 \mathrm{~min}$ were shifted to the blue by $19 \mathrm{~nm}$ and $44 \mathrm{~nm}$, respectively, compared with $\lambda_{L}$ at $0 \mathrm{~min}$. Thus, this suggests that we can control the aspect ratios of gold NRs by adjusting electrolysis time after removing the silver plate. In contrary to the obvious shift of $\lambda_{L}, \lambda_{T}$ was relatively unchanged to be present at $520 \mathrm{~nm}$.

The TEM images of gold NRs in Figure 5 support the phenomena observed with the absorption spectra of Figure 4 . When the electric current was applied additionally for $5 \mathrm{~min}$ after removing the silver plate, aspect ratios as well as diameters and lengths increased, indicating that gold NRs were still growing. However, when the electric current was applied additionally for $10 \mathrm{~min}$ and $15 \mathrm{~min}$ after removing

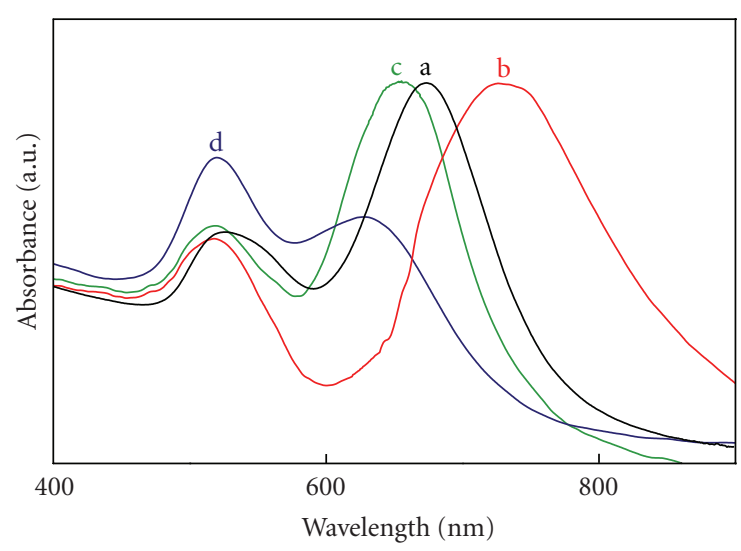

FIgURE 4: Absorption spectra of aqueous gold NR solutions, electrolyzed at $5 \mathrm{~mA}$ for $10 \mathrm{~min}$ with a silver plate and then for $0 \mathrm{~min}$ (a), $5 \mathrm{~min}$ (b), $10 \mathrm{~min}$ (c), and $15 \mathrm{~min}$ (d) additionally after removing the silver plate.

the silver plate, the aspect ratios of gold NRs decreased although both of the lengths and the diameters increased apparently compared with the respective ones at $0 \mathrm{~min}$. These suggest that the aspect ratios of gold NRs can be regulated by adjusting the amount of silver ions present in the reaction system. This indicates that the average aspect ratio of gold NRs increased in the beginning and then decreased when the electric current was applied in the absence of a silver plate. It is known that the aspect ratios of gold NRs increase with the concentration increase of silver ions [20, 23, 32, 33]. The aspect ratios of gold NRs increased for $5 \mathrm{~min}$ and then decreased for further electrolysis time in the absence of a silver plate (Table 2). The mean aspect ratio of gold NRs increased for $5 \mathrm{~min}$ because silver deposition on the $\{110\}$ facets took place to inhibit growth on the sides of gold NRs. Thus, gold grew on the low-energy $\{100\}$ facets to elongate gold NRs for the early time after removing the silver plate. However, the average aspect ratio of gold NRs decreased for further electrolysis time in the absence of a silver plate because silver deposition occurred no longer to inhibit gold deposition on the high-energy $\{110\}$ facets.

The visible absorption spectra of aqueous gold NR solutions in Figure 6 reveal that the aspect ratios of gold NRs can be controlled finely by adjusting electrolysis time in the presence of a silver plate. When the molar ratio of gold ions to silver ions remained invariant during the electrolysis, both $\lambda_{L}$ and $A R$ increased largely and monotonically with electrolysis time (Figure 6 and Table 3 ). $\lambda_{L}$ at $25 \mathrm{~min}$ is larger by $149 \mathrm{~nm}$ 


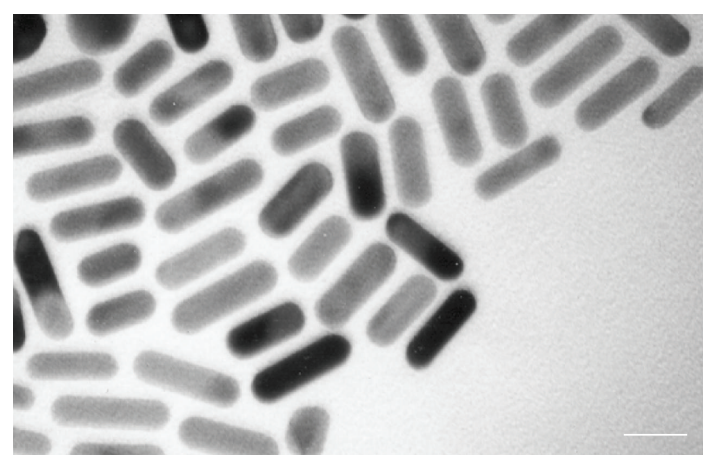

(a)

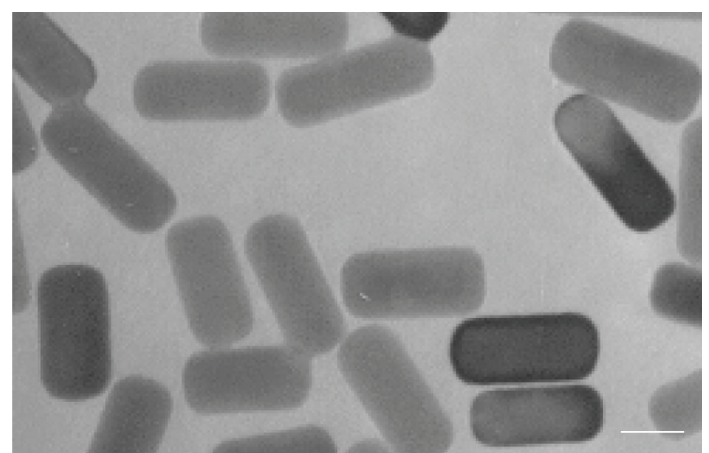

(c)

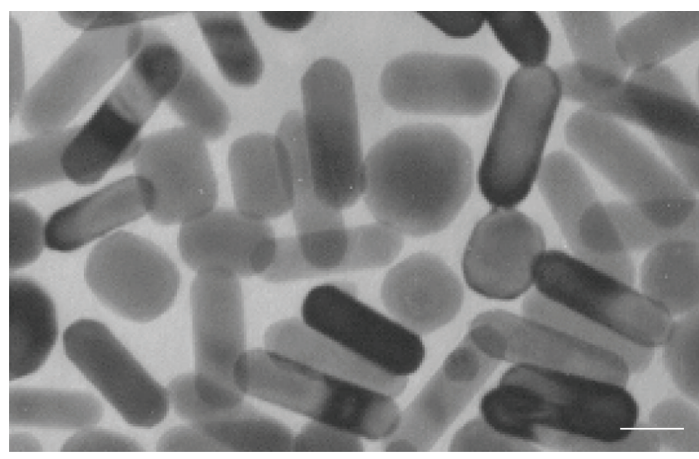

(b)

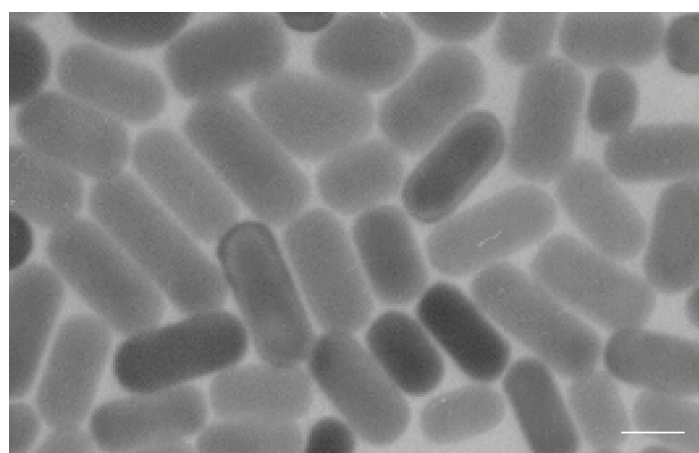

(d)

Figure 5: TEM images of modified gold NRs, electrolyzed at $5 \mathrm{~mA}$ for $10 \mathrm{~min}$ with a silver plate and then for $0 \mathrm{~min}$ (a), $5 \mathrm{~min}$ (b), $10 \mathrm{~min}$ (c), and $15 \mathrm{~min}$ (d) additionally after removing the silver plate. Each scale bar indicates $25 \mathrm{~nm}$.

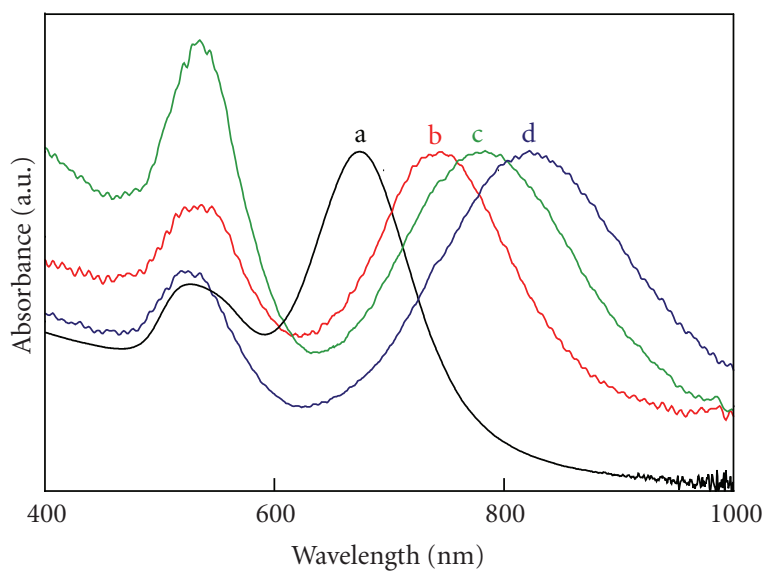

FIGURE 6: Absorption spectra of aqueous gold NR colloidal solutions electrolyzed at $5 \mathrm{~mA}$ with a silver plate for $10 \mathrm{~min}$ (a), $15 \mathrm{~min}$ (b), $20 \mathrm{~min}$ (c), and $25 \mathrm{~min}(\mathrm{~d})$.

than $\lambda_{L}$ at 10 min while $A R$ at $25 \mathrm{~min}$ is greater by 1.8 than $A R$ at $10 \mathrm{~min}$. Together with Figure 4, Figure 6 indicates that the presence of silver ions in the electrolytic solution is critically vital for the elongation of gold NRs. It has been reported [32] that the aspect ratios of gold NRs increase with the total area of an immersed silver plate. Thus, the amount and the release speed of silver ions can be adjusted to control the aspect ratios of gold NRs finely. It would be fundamentally important to explore how the presence or absence of a
TABLE 3: Wavelengths at longitudinal absorption peaks $\left(\lambda_{L}\right)$ and average aspect ratios $(A R)$ for the gold NRs of the samples described in Figure 6.

\begin{tabular}{lccc}
\hline Figure & Time $(\min )^{\mathrm{a}}$ & $\lambda_{L}(\mathrm{~nm})$ & $A R$ \\
\hline Figure 6(a) & 10 & 674 & 2.7 \\
Figure 6(b) & 15 & 745 & 3.4 \\
Figure 6(c) & 20 & 783 & 4.0 \\
Figure 6(d) & 25 & 823 & 4.5 \\
\hline
\end{tabular}

alectrolysis time in the presence of a silver plate.

silver plate could control the aspect ratios of gold NRs in our process. The report on silver underpotential deposition (UPD) on growing gold nanoparticles by Guyot-Sionnest has provided some useful insight into the role of silver ions and a possible rationale for excess silver ions in a solution [4042]. Gold NRs grown using CTAB-protected gold seeds in the presence of $\mathrm{Ag}^{+}$ions were reported [32-35] to bear $\{110\}$ facets on the sides of gold NRs and $\{100\}$ facets on the ends of gold NRs. Silver UPD is the reduction of $\mathrm{Ag}^{+}$to $\mathrm{Ag}^{0}$ at a metal substrate with a surface potential less than the standard reduction potential of $\mathrm{Ag}^{+}$. A great positive shift in potential for silver UPD on gold surfaces was observed on $\{110\}$ surfaces compared to the $\{100\}$ or $\{111\}$ facets [40-42]. The deposition of silver on the sides of gold NRs becomes faster than that on the ends of gold NRs [33, 40-42]. Fast silver deposition followed by strong CTAB binding inhibits growth on the sides of gold NRs and leads to preferential growth 
at the ends of gold NRs. Presenting the crystalline structure of gold NRs, two recent papers $[43,44]$ have provided new insights in the growth mechanisms of gold NRs having a wide range of morphologies on the nanoscale.

\section{Conclusion}

The aspect ratios of gold NRs have been controlled in two electrochemical ways. Firstly, they have been finely modified by changing the amount of a growth solution containing small gold clusters in the presence of already prepared gold NRs as seeds. Secondly, they could be controlled well by adjusting electrolysis time in the presence or absence of a silver plate. While the gold concentration ratio of the growth solution to the seed solution was critical in the former method for the control of the aspect ratios of gold NRs, the relative molar ratio of gold ions to silver ions was important in the latter way. The aspect ratios of gold nanorods decreased with an increase of electrolysis time in the absence of a silver plate, but they increased with an increase of electrolysis time in the presence of a silver plate. This indicates that the presence of silver ions in the electrolytic solution is critically vital for the elongation of gold NRs.

\section{Acknowledgments}

This work was supported by research grants through the National Research Foundation of Korea funded by the Ministry of Education, Science, and Technology (20100015806 and 2010-0001216). J.-Y. Kim also acknowledges a BK21 scholarship.

\section{References}

[1] J. H. Kim, Y. Jung, J. W. Chung, B. K. An, and S. Y. Park, "Fabrication of a patterned assembly of semiconducting organic nanowires," Small, vol. 5, no. 7, pp. 804-807, 2009.

[2] S. J. Kim, C. S. Ah, and D. J. Jang, "Optical fabrication of hollow platinum nanospheres by excavating the silver core of Ag@Pt nanoparticles," Advanced Materials, vol. 19, no. 8, pp. 1064-1068, 2007.

[3] J. Y. Kim, S. Lee, K. H. Yoo, and D. J. Jang, "Coulomb blockade effect and negative differential resistance in the electronic transport of bacteriorhodopsin," Applied Physics Letters, vol. 94, no. 15, Article ID 153301, 3 pages, 2009.

[4] J. Y. Kim, S. J. Kim, and D. J. Jang, "Laser-induced shape transformation and electrophoretic analysis of triangular silver nanoplates," Journal of Separation Science, vol. 32, no. 23-24, pp. 4161-4166, 2009.

[5] J. W. Hu, J. F. Li, B. Ren, D. Y. Wu, S. G. Sun, and Z. Q. Tian, "Palladium-coated gold nanoparticles with a controlled shell thickness used as surface-enhanced raman scattering substrate," Journal of Physical Chemistry C, vol. 111, no. 3, pp. 1105-1112, 2007.

[6] H. Song, R. He, K. Wang et al., "Anti-HIF- $1 \alpha$ antibodyconjugated pluronic triblock copolymers encapsulated with Paclitaxel for tumor targeting therapy," Biomaterials, vol. 31, no. 8, pp. 2302-2312, 2010.

[7] J. Y. Kim, D. H. Lee, S. J. Kim, and D. J. Jang, "Preferentially linear connection of gold nanoparticles in derivatization with phosphorothioate oligonucleotides," Journal of Colloid and Interface Science, vol. 326, no. 2, pp. 387-391, 2008.

[8] P. Klason, O. Nur, and M. Willander, "Electrical characteristics and stability of gold and palladium Schottky contacts on $\mathrm{ZnO}$ nanorods," Nanotechnology, vol. 19, no. 47, Article ID 475202, 5 pages, 2008.

[9] E.-S. Jang, X. Chen, J.-H. Won et al., "Soft-solution route to $\mathrm{ZnO}$ nanowall array with low threshold power density," Applied Physics Letters, vol. 97, no. 4, Article ID 043109, 3 pages, 2010.

[10] J.-Y. Kim, M. R. Kim, S.-Y. Park, and D.-J. Jang, "Hydrothermal growth control of ZnSe-N2H4 nanobelts," CrystEngCommunity, vol. 12, no. 6, pp. 1803-1808, 2010.

[11] O. R. Miranda and T. S. Ahmadi, "Effects of intensity and energy of CW UV light on the growth of gold nanorods," Journal of Physical Chemistry B, vol. 109, no. 33, pp. 1572415734, 2005.

[12] P. Klason, T. Moe Børseth, Q. X. Zhao et al., “Temperature dependence and decay times of zinc and oxygen vacancy related photoluminescence bands in zinc oxide," Solid State Communications, vol. 145, no. 5-6, pp. 321-326, 2008.

[13] E. S. A. M. Al-Sherbini, "UV-visible light reshaping of gold nanorods," Materials Chemistry and Physics, vol. 121, no. 1-2, pp. 349-353, 2010.

[14] X. Huang, I. H. El-Sayed, W. Qian, and M. A. El-Sayed, "Cancer cell imaging and photothermal therapy in the nearinfrared region by using gold nanorods," Journal of the American Chemical Society, vol. 128, no. 6, pp. 2115-2120, 2006.

[15] D. P. Yang and D. X. Cui, "Advances and prospects of gold nanorods," Chemistry-An Asian Journal, vol. 3, no. 12, pp. 2010-2022, 2008.

[16] H. Y. Guo, L. H. Lu, C. Wu, J. G. Pan, and J. W. Hu, "SERS tagged gold nanorod probes for immunoassay application," Acta Chimica Sinica, vol. 67, no. 14, pp. 1603-1608, 2009.

[17] K. Okitsu, Y. Mizukoshi, T. A. Yamamoto, Y. Maeda, and Y. Nagata, "Sonochemical synthesis of gold nanoparticles on chitosan," Materials Letters, vol. 61, no. 16, pp. 3429-3431, 2007.

[18] J. Pérez-Juste, L. M. Liz-Marzán, S. Carnie, D. Y. C. Chan, and P. Mulvaney, "Electric-field-directed growth of gold nanorods in aqueous surfactant solutions," Advanced Functional Materials, vol. 14, no. 6, pp. 571-579, 2004.

[19] R. Zou, X. Guo, J. Yang et al., "Selective etching of gold nanorods by ferric chloride at room temperature," CrystEngCommunity, vol. 11, no. 12, pp. 2797-2803, 2009.

[20] F. Kim, J. H. Song, and P. Yang, "Photochemical synthesis of gold nanorods," Journal of the American Chemical Society, vol. 124, no. 48, pp. 14316-14317, 2002.

[21] S. Roorda, T. Van Dillen, A. Polman, C. Graf, A. Van Blaaderen, and B. J. Kooi, "Aligned gold nanorods in silica made by ion irradiation of core-shell colloidal particles," Advanced Materials, vol. 16, no. 3, pp. 235-237, 2004.

[22] T. K. Sau and C. J. Murphy, "Seeded high yield synthesis of short Au nanorods in aqueous solution," Langmuir, vol. 20, no. 15, pp. 6414-6420, 2004.

[23] H. Guo, F. Ruan, L. Lu et al., "Correlating the shape, surface plasmon resonance, and surface-enhanced raman scattering of gold nanorods," Journal of Physical Chemistry C, vol. 113, no. 24, pp. 10459-10464, 2009.

[24] C. J. Murphy and N. R. Jana, "Controlling the aspect ratio of inorganic nanorods and nanowires," Advanced Materials, vol. 14 , no. 1 , pp. 80-82, 2002.

[25] K. Okitsu, K. Sharyo, and R. Nishimura, "One-pot synthesis of gold nanorods by ultrasonic irradiation: the effect of $\mathrm{pH}$ on 
the shape of the gold nanorods and nanoparticles," Langmuir, vol. 25, no. 14, pp. 7786-7790, 2009.

[26] O. R. Miranda, N. R. Dollahon, and T. S. Ahmadi, "Critical concentrations and role of ascorbic acid (vitamin $\mathrm{C}$ ) in the crystallization of gold nanorods within hexadecyltrimethyl ammonium bromide (CTAB)/tetraoctyl ammonium bromide (TOAB) micelles," Crystal Growth and Design, vol. 6, no. 12, pp. 2747-2753, 2006.

[27] Y. Niidome, K. Nishioka, H. Kawasaki, and S. Yamada, "Rapid synthesis of gold nanorods by the combination of chemical reduction and photoirradiation processes; morphological changes depending on the growing processes," Chemical Communications, vol. 9, no. 18, pp. 2376-2377, 2003.

[28] YU. Y. Yu, S. S. Chang, C. L. Lee, and C. R. C. Wang, "Gold nanorods: electrochemical synthesis and optical properties," Journal of Physical Chemistry B, vol. 101, no. 34, pp. 66616664, 1997.

[29] M. B. Mohamed, K. Z. Ismail, S. Link, and M. A. El-Sayed, "Thermal reshaping of gold nanorods in micelles," The Journal of Physical Chemistry B, vol. 102, no. 47, pp. 9370-9374, 1998.

[30] Z. L. Wang, R. P. Gao, B. Nikoobakht, and M. A. El-Sayed, "Surface reconstruction of the unstable $\{110\}$ surface in gold nanorods," Journal of Physical Chemistry B, vol. 104, no. 23, pp. 5417-5420, 2000.

[31] B. Nikoobakht, J. Wang, and M. A. El-Sayed, "Surfaceenhanced Raman scattering of molecules adsorbed on gold nanorods: off-surface plasmon resonance condition," Chemical Physics Letters, vol. 366, no. 1-2, pp. 17-23, 2002.

[32] S. S. Chang, C. W. Shih, C. D. Chen, W. C. Lai, and C. R. C. Wang, "The shape transition of gold nanorods," Langmuir, vol. 15, no. 3, pp. 701-709, 1999.

[33] J. Hee Song, F. Kim, D. Kim, and P. Yang, "Crystal overgrowth on gold nanorods: tuning the shape, facet, aspect ratio, and composition of the nanorods," Chemistry - A European Journal, vol. 11, no. 3, pp. 910-916, 2005.

[34] C. J. Huang, P. H. Chiu, Y. H. Wang, and C. F. Yang, "Synthesis of the gold nanodumbbells by electrochemical method," Journal of Colloid and Interface Science, vol. 303, no. 2, pp. 430-436, 2006.

[35] B. Nikoobakht and M. A. El-Sayed, "Preparation and growth mechanism of gold nanorods (NRs) using seed-mediated growth method," Chemistry of Materials, vol. 15, no. 10, pp. 1957-1962, 2003.

[36] H. Ma, B. Yin, S. Wang et al., "Synthesis of silver and gold nanoparticles by a novel electrochemical method," ChemPhysChem, vol. 5, no. 1, pp. 68-75, 2004.

[37] G. Canizal, J. A. Ascencio, J. Gardea-Torresday, and M. JoséYacamán, "Multiple twinned gold nanorods grown by bioreduction techniques," Journal of Nanoparticle Research, vol. 3, no. 5-6, pp. 475-481, 2001.

[38] M. José Yacamán, J. A. Ascencio, and G. Canizal, “Observation of surface relaxation surface steps and surface reconstruction in gold nanorods," Surface Science, vol. 486, no. 1-2, pp. L449L453, 2001.

[39] H. A. Keul, M. Möller, and M. R. Bockstaller, "Structural evolution of gold nanorods during controlled secondary growth," Langmuir, vol. 23, no. 20, pp. 10307-10315, 2007.

[40] C. J. Orendorff and C. J. Murphy, "Quantitation of metal content in the silver-assisted growth of gold nanorods," Journal of Physical Chemistry B, vol. 110, no. 9, pp. 3990-3994, 2006.

[41] M. Liu and P. Guyot-Sionnest, "Mechanism of silver(I)assisted growth of gold nanorods and bipyramids," Journal of Physical Chemistry B, vol. 109, no. 47, pp. 22192-22200, 2005.

[42] T. S. Sreeprasad, A. K. Samal, and T. Pradeep, "Body- or tipcontrolled reactivity of gold nanorods and their conversion to particles through other anisotropic structures," Langmuir, vol. 23, no. 18, pp. 9463-9471, 2007.

[43] E. Carbó-Argibay, B. Rodríguez-González, S. Gómez-Graña et al., "The crystalline structure of gold nanorods revisited: evidence for higher-index lateral facets," Angewandte ChemieInternational Edition, vol. 49, no. 49, pp. 9397-9400, 2010.

[44] H. Katz-Boon, C. J. Rossouw, M. Weyland, A. M. Funston, P. Mulvaney, and J. Etheridge, "Three-dimensional morphology and crystallography of gold nanorods," Nano Letters, vol. 11, no. 1, pp. 273-278, 2011. 

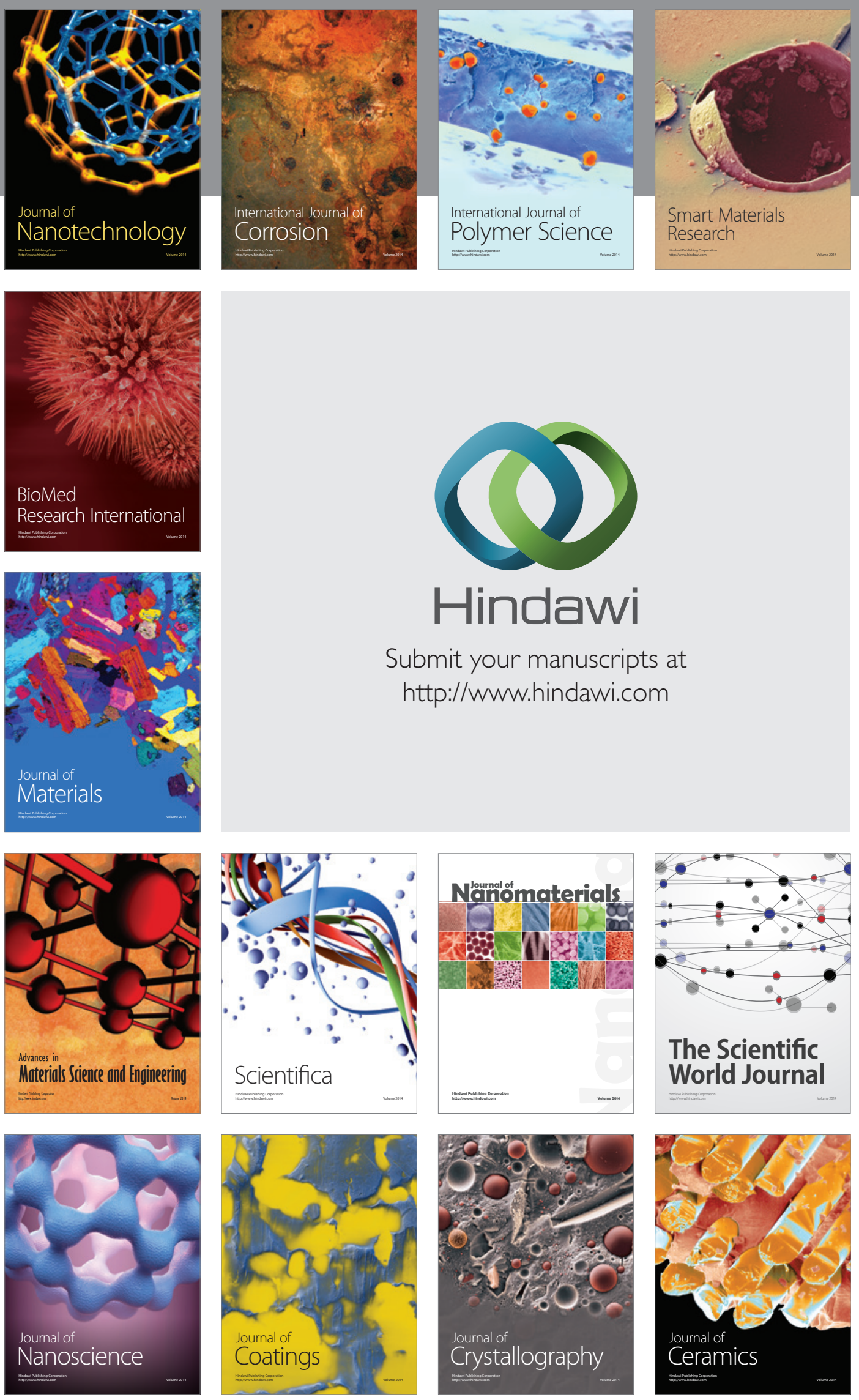

The Scientific World Journal

Submit your manuscripts at

http://www.hindawi.com

\section{World Journal}

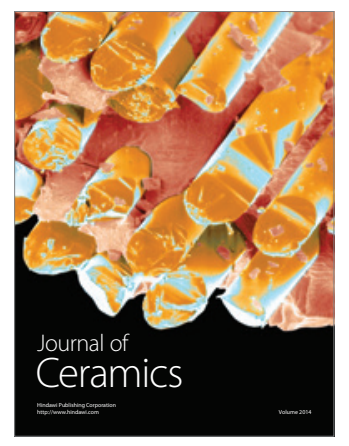

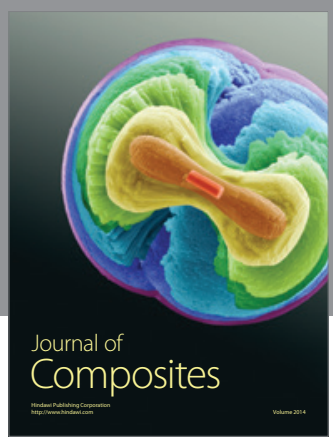
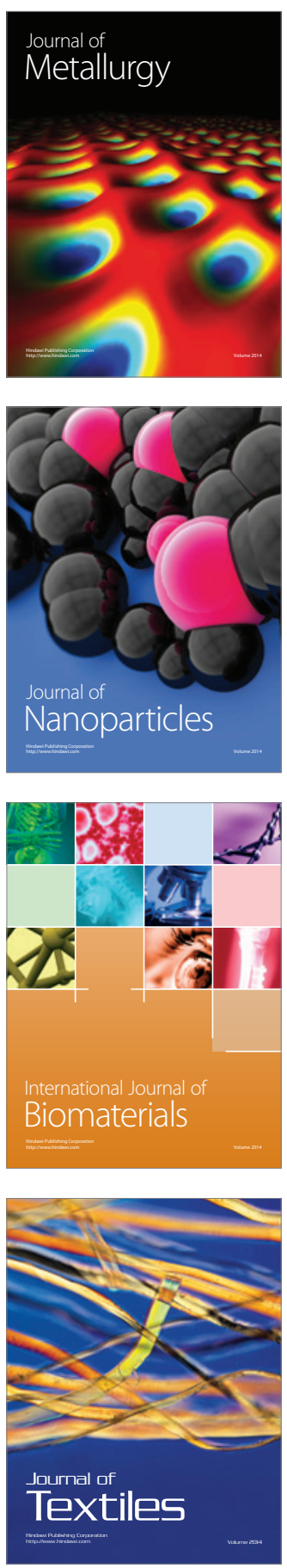